\title{
Determinants of sleep quality among pregnant women in China: A cross-sectional survey
}

\author{
Ying Yang, Jing Mao, Zhiying Ye, Jie Li*, Huimin Zhao and Yueting Liu \\ School of Nursing, Tongji Medical College, Huazhong University of Science and Technology, Wuhan, China
}

\begin{abstract}
Background: Sleep problems are common during pregnancy. Few studies are currently available regarding the determinants of sleep quality among pregnant women in China. The aim of the present study was to (a) calculate the prevalence of sleep disorder during pregnancy, (b) examine the difference in sleep quality among three trimesters, and (c) identify determinants of sleep quality in pregnant women.

Methods: This study was designed as a cross-sectional survey. 500 pregnant women were recruited at the outpatient department of obstetrics and gynecology of two teaching hospitals in central China. Five self-report questionnaires were used for gathering data, including information of sample characteristics, sleep quality (Pittsburgh Sleep Quality Index, PSQI), prenatal depression (the Edinburgh Postnatal Depression Scale, EPDS), perceived stress (Perceived Stress Scale, PSS) and perceived social support (Multidimensional Scale of Perceived Social Support, MSPSS).

Results: A total of 454 pregnant women participated in the study between December 2013 and July 2014. 87\% pregnant women experience sleep disorder (PSQI score $>5)$. Poorer global sleep quality, subjective sleep quality, lower sleep efficiency and sleep disturbances were most prevalent during third trimester. The significant contributors of sleep quality for pregnant women were prenatal depression, age and gestational age.

Conclusions: Sleep disorder is a common problem for pregnant women in China. Depressive symptoms, increased age and gestational age are determinants of sleep quality. Health care professionals should identify determinants to conduct preventive intervention.
\end{abstract}

\begin{abstract}
Abbreviations
BMI: Body mass index; PSQI: The Pittsburgh sleep quality index; EPDS: The Edinburgh postnatal depression scale; PSS: Perceived stress scale; MSPSS: Multidimensional scale of perceived social support

\section{Introduction}

Pregnancy is a process that creates significant anatomical, physiological, and biochemical changes in a woman's life. These changes affect the physical and emotional behaviors of women and may lead to sleep disturbances, even in women without prior sleep problems [1]. Moreover, sleep changes during pregnancy may not be returned to the same sleep quality before pregnancy for years [2]. The National Sleep Foundation [3] noted that $78 \%$ of pregnant women reported more sleep disturbances during pregnancy than at any other time in their lives. What's more, most pregnant women (84\%) report sleep disturbances of some severity, and 30\% report that they rarely or never get a good night's sleep during pregnancy [4]. A study based on Chinese population showed that $35.8 \%$ of pregnant women suffer from sleep disorders [5]. Consequently, poor sleep quality during pregnancy has become a frequent problem threatening pregnant women's health.
\end{abstract}

Assessment of sleep quality is clinically relevant in view of the previous findings that sleep quality may be associated with some factors, such as mood disorders (e.g., depression, stress) and gestational age [6,7]. Women's body changes dramatically in a relatively short time during pregnancy, both physiologically and psychologically, which results in a significant alternation of sleep pattern [6]. Women experienced sleep disturbances as early as during the first trimester of pregnancy [8]. As pregnancy proceeds, both the number and duration of sleep disorders increase [6]. Sut et al. [9] and Facco et al. [10] indicated that the risk of poor sleep quality increased in the second and third trimester when compared with the first trimester. Depression symptom was previously indicated to be associated with sleep disturbances during pregnancy [11]. Prenatal depression as well as postpartum depression were strongly linked with sleep quality [12]. Consistent with this, depressive pregnant women reportedly have various types of insomnia symptoms and decreased sleep efficiency $[13,14]$.

Sleep disorders may influence pregnancy outcomes and may manifest differently in different cultural and social societies [15]. However, few studies have investigated sleep quality during pregnancy in China. Thus, we conducted this cross-sectional survey to explore the sleep quality in China, with the purpose of (1) calculating the prevalence of sleep disorder during pregnancy, (2) examining the difference in sleep quality among three trimesters, and (3) identifying determinants of sleep quality in pregnant women.

\section{Materials and methods}

\section{Design and sample}

The cross-sectional survey was conducted at the outpatient

Correspondence to: Jie Li, School of Nursing, Tongji Medical College, Huazhong University of Science and Technology, Wuhan, China, Tel: 862783692635; E-mail: Cherrygo10@163.com

Key words: sleep quality, pregnant women, depression, China

Received: April 19, 2017; Accepted: May 05, 2017; Published: May 09, 2017 
department of obstetrics and gynecology of two teaching hospitals in central China between December 2013 and July 2014. 500 pregnant women meet following inclusion criteria were recruited in this study: (1) pregnant women aged 18 and above, (2) welling to participate in the study, (3) have basic ability of reading and understanding, and (4) mentally competent to give informed consent. Participants eligible for inclusion were provided with comprehensive information on reasons for the research, advantages, results, confidentiality, and methods of the research. Three well-trained research assistants obtained informed consent and collected self-report questionnaires from the participants.

\section{Instruments}

Five forms were used as data collection instruments: (1) a Personal Information Form, to determine the participants' demographic, personal characteristics and Gestational age etc. (2) the Pittsburgh Sleep Quality Index (PSQI), (3) the Edinburgh Postnatal Depression Scale (EPDS), (4) the Perceived Stress Scale (PSS), and (5) the Multidimensional Scale of Perceived Social Support (MSPSS).

PSQI is self-report measure that assesses sleep quality and disturbances over a 1-month interval, which was developed by Buysse et al. [16]. It includes 19 items, generating 7 component scores: subjective sleep quality, sleep latency, sleep duration, habitual sleep efficiency, sleep disturbances, use of sleeping medication, and daytime dysfunction. A global score is obtained by summing the 7 component scores and has a possible range of $0 \sim 21$ points. Higher scores indicate poorer sleep quality. A global score higher than 5 is assessed as poor sleep quality or sleep disorder. This cutoff point has good psychometric properties with a diagnostic sensitivity of $89.6 \%$ and specificity of $86.5 \%$ in differentiating good and poor sleepers [16]. The validity and reliability of the Chinese version of the PSQI were reported by Liu et al. [17] in 1996 (Cronbach's $\alpha=0.8420$ ).

EPDS is a self-report questionnaire of postnatal depression, developed by Cox et al. [18]. Cox et al. also evidenced it suitable for the screening of prenatal depression in 2003 [19]. EPDS contains ten multiple-choice questions, with four possible answers for each question and $0 \sim 3$ points for each answer. The total score ranges from 0 to 30 with higher scores indicating more severe depressive symptoms [18]. EPDS was translated into Chinese version by Pen et al. [20]. The Chinese version of EPDS was applied to assess prenatal depression in Chinese mainland population (Cronbach's $\alpha=0.79$ ), with the sensitivity and specificity of $80.00 \%$ and $83.03 \%$, respectively [21]. The recommended cut-off score of EPDS for Chinese mainland population is 9.5, a total score of 9.5 or greater indicates prenatal depression.

PSS designed by Cohen et al. [22] was utilized to measure the degree to which situations in one's life are appraised as stressful. PSS is a validated instrument consisting of 10 multiple choice questions individually scored 0 to 4 (with requisite reverse scoring for 4 items) [22]. The reliability and validity of Chinese version of 10-iterm PSS were evaluated among Chinese population, with a Cronbach's $\alpha$ of $0.83[23]$.

MSPSS is a 12-item self-report instrument that assesses the adequacy of one's perceived social support from family, friends and significant others [24]. MSPSS consists of three subscales (family's support, friends' support and significant others' support) and 12 items. Item scores range from 1 to 7 , with responses averaged to create total and sub-scale scores. In all cases, higher scores indicate greater perceived social support [25].

\section{Statistical analysis}

Statistical analysis was performed by the Statistical Package for Social Sciences (SPSS) version 21.0 in this study. Descriptive statistics including means, frequency, and standard deviations etc. were calculated for all the variables. One-way ANOVA was operated to reveal the difference of sleep quality among three trimesters. A Pearson's correlation matrix was computed to examine the bivariate correlations between sleep quality and each potential predictor variable. Multivariable stepwise linear regression was applied to confirm the determinants of sleep quality. In all analyses, a $P$-value of $\leq 0.05$ was considered significant.

\section{Results}

\section{General characteristics}

Among the 500 pregnant women admitted during the study period, 454 (90.8\%) between 19 and 40 years old (mean 28.5) finished our survey. Of the 454 participants, $22(4.8 \%)$ were in first trimester, $246(54.2 \%)$ in second trimester, and $186(41.0 \%)$ in third trimester. The demographic characteristics are summarized in Table 1.

The mean EPDS (depression) score was $8.49 \pm 4.44$ (range 0 24), of which 181 pregnant women (39.9\%) were identified as prenatal depression (EPDS score 29.5 ). Besides, the score of PSS (stress) and MSPSS (social support) were $13.23 \pm 6.05$, and $64.30 \pm 11.19$, respectively.

\section{Sleep quality}

PSQI score and the results of one-way ANOVA are listed in Table 2. The global PSQI score in our sample was 7.68 \pm 1.96 (range 4 15), with 395 pregnant women (87.0\%) classified as sleep disorder (global PSQI score $>5$ ). The number of poor sleeper in first, second, and third trimester were $18(81.8 \%), 215(87.4 \%)$, and $162(87.1 \%)$, respectively. Significant differences of global PSQI score and three component scale (subjective sleep quality, habitual sleep efficiency, and sleep

Table 1. Demographic characteristics of pregnant women $(\mathrm{N}=454)$.

\begin{tabular}{|l|c|}
\hline Variable & N (\%) \\
\hline BMI & $14(3.1)$ \\
\hline Underweight $(\mathrm{BMI}<19)$ & $247(54.4)$ \\
\hline Normal weight $(19 \leq \mathrm{BMI} \leq 25)$ & $158(34.8)$ \\
\hline Overweight $(25<\mathrm{BMI} \leq 30)$ & $35(7.7)$ \\
\hline Obesity (BMI $>30)$ & \\
\hline Marital status & $450(99.1)$ \\
\hline Married & $4(0.9)$ \\
\hline Single & \\
\hline Working status & $163(35.9)$ \\
\hline Employed & $291(64.1)$ \\
\hline Unemployed & $271(59.7)$ \\
\hline Educational level & $183(40.3)$ \\
\hline Low educational level (below bachelor's degree) & \\
\hline High educational level (bachelor's degree or higher) & $66(14.5)$ \\
\hline Levels of income (yuan per month) & $187(41.2)$ \\
\hline$\leq 2000$ & $96(21.2)$ \\
\hline $2000 \sim 4000$ & $105(23.1)$ \\
\hline $4000 \sim 6000$ & \\
\hline$\geq 6000$ & $22(4.8)$ \\
\hline Gestational age & $186(41.0)$ \\
\hline First trimester & \\
\hline Second trimester & \\
\hline Third trimester & \\
\hline
\end{tabular}


Table 2. PSQI score and the differences among three trimesters.

\begin{tabular}{|c|c|c|c|c|c|c|}
\hline \multirow[t]{2}{*}{ Components } & \multirow[b]{2}{*}{$\begin{array}{c}\text { Mean } \\
\text { score } \\
(n=454)\end{array}$} & \multirow[b]{2}{*}{$\begin{array}{c}\text { First } \\
\text { trimester } \\
(\mathbf{n}=22)\end{array}$} & \multicolumn{2}{|c|}{ Gestational age } & \multirow[t]{2}{*}{$F$} & \multirow[t]{2}{*}{$P$} \\
\hline & & & $\begin{array}{c}\text { Second } \\
\text { trimester } \\
(\mathrm{n}=\mathbf{2 4 6})\end{array}$ & $\begin{array}{c}\text { Third } \\
\text { trimester } \\
(\mathbf{n}=186)\end{array}$ & & \\
\hline Global score & $7.68 \pm 1.96$ & $7.18 \pm 1.97$ & $7.51 \pm 1.83$ & $7.96 \pm 2.10$ & 3.58 & 0.03 \\
\hline \multicolumn{7}{|l|}{ Component score } \\
\hline Subjective sleep quality & $1.14 \pm 0.59$ & $1.00 \pm 0.53$ & $1.08 \pm 0.56$ & $1.23 \pm 0.63$ & 3.80 & 0.02 \\
\hline Sleep latency & $1.29 \pm 0.85$ & $1.18 \pm 0.96$ & $1.28 \pm 0.81$ & $1.32 \pm 0.89$ & 0.29 & 0.75 \\
\hline Sleep duration & $0.10 \pm 0.08$ & $0.14 \pm 0.35$ & $0.07 \pm 0.31$ & $0.15 \pm 0.52$ & 1.90 & 0.15 \\
\hline Habitual sleep efficiency & $0.96 \pm 0.49$ & $0.75 \pm 0.67$ & $0.78 \pm 0.54$ & $0.86 \pm 0.79$ & 9.10 & 0.00 \\
\hline Sleep disturbances & $1.50 \pm 0.56$ & $1.23 \pm 0.43$ & $1.44 \pm 0.54$ & $1.61 \pm 0.58$ & 8.13 & 0.00 \\
\hline Use of sleeping medication & $0.05 \pm 0.03$ & $0.00 \pm 0.00$ & $0.06 \pm 0.35$ & $0.04 \pm 0.33$ & 0.42 & 0.66 \\
\hline Daytime dysfunction & $0.60 \pm 0.58$ & $0.64 \pm 0.66$ & $0.58 \pm 0.59$ & $0.62 \pm 0.55$ & 0.26 & 0.77 \\
\hline
\end{tabular}

Table 3. Correlation coefficients between sleep quality and other variables.

\begin{tabular}{|l|c|c|}
\hline Variable & $\boldsymbol{r}$ & $\boldsymbol{P}$ \\
\hline Age & 0.12 & $\leq 0.01$ \\
\hline BMI & 0.04 & \\
\hline Gestational age & 0.15 & $\leq 0.01$ \\
\hline EPDS score & 0.43 & $\leq 0.01$ \\
\hline PSS score & 0.32 & $\leq 0.01$ \\
\hline MSPSS score & -0.17 & \\
\hline
\end{tabular}

Table 4. Results of multiple linear regression model predicting sleep quality.

\begin{tabular}{|l|c|c|c|c|}
\hline Predictors & Beta & $\boldsymbol{S E}$ Beta & $\boldsymbol{t}$ & $\boldsymbol{P}$ \\
\hline Age & 0.09 & 0.16 & 3.79 & $<0.001$ \\
\hline Gestational age & 0.04 & 0.14 & 3.46 & $<0.001$ \\
\hline EPDS score & 0.19 & 0.44 & 10.57 & $<0.001$ \\
\hline
\end{tabular}

disturbances) scores were found among three trimesters $(\mathrm{P}<0.05)$.

When compared with second trimester, pregnant women in third trimester experienced higher score of global PSQI, subjective sleep quality, habitual sleep efficiency, and sleep disturbances $(\mathrm{P}<0.05)$. When compared with first trimester, pregnant women in third trimester experienced higher score of habitual sleep efficiency and sleep disturbances $(\mathrm{P}<0.05)$.

\section{Bivariate associations}

Pearson coefficients were computed to identify correlates of sleep quality in pregnant women. As shown in Table 3, age, gestational age, EPDS score, and PSS score were positively correlated with poorer sleep quality.

\section{Multivariable linear regression}

The results of the standard multivariable linear regression model in which all the variables were entered simultaneously are presented in Table $4(\mathrm{~F}=44.149, \mathrm{R} 2=0.23, \mathrm{P}<0.001)$. Age, gestational age, and prenatal depression were significant determinants of sleep quality $(\mathrm{P}<0.001)$, which predicted $22.7 \%$ of the variance in sleep quality.

\section{Discussion}

Women experience significant sleep problems during pregnancy [6], and poor sleep quality in pregnancy has been associated with preterm birth [26]. Sleep disturbances seen in pregnancy may be linked to adverse outcomes, such as gestational hypertension and cesarean birth [27]. Furthermore, Zafarghandi et al. [28] reported that the quality and duration of sleep can affect birth type, labor length, birth weight, and Apgar score. The prevalence of sleep disorder in the present study was $87.0 \%$, in which the proportion was reported by
$81.80 \%, 87.40 \%$ and $87.10 \%$ during the three trimesters, respectively. Our survey declared a higher prevalence of sleep disorder than those of Mindell et al. [6] (76\%), Xie et al. [29] (64\%) and Van Ravesteyn et al. [30] (39\%). These findings indicate that at least one-third of pregnant women experience poor sleep quality during any part of pregnancy.

We found support from correlation analysis and multiple regression model in understanding sleep quality of pregnant women. The important determinants of sleep quality were age, gestational age, and prenatal depression.

Maternal age was identified as a determinant of sleep disorder in our study, suggesting that general sleep quality declines as age growths among pregnant women. Hung et al. [7] and Zhang et al. [5] have reported the similar result. As a potential high-risk factor, women with advanced maternal age were more likely affected by physiological and psychological factors [31], thus leading to the deterioration of sleep quality [32].

Significant association between gestational age and sleep quality was discovered, showing that general sleep quality declines as pregnancy proceeds. When compared with the first and second trimester, significant deteriorations in sleep quality in the third trimester were observed. Poorer global sleep quality, subjective sleep quality, lower sleep efficiency and sleep disturbances were most prevalent during third trimester. These findings were supported by several studies $[9,10]$, including a report of Chinese pregnant women population [33]. The sleep patterns of most pregnant women changed during pregnancy, which might be the reason [6]. However, future researches are still needed to clear the in-depth connections in regarding to sleep quality among three trimesters.

A relationship between prenatal depression and sleep quality in pregnant women has previously been demonstrated, showing that higher levels of prenatal depression predicted poorer sleep quality, as depression is one of the main psychological factors contributing to sleep complaints $[7,14,34,35]$. The association between poor sleep quality and depressed mood has also been shown in epidemiologic studies of sleep in the general population [36], and with postpartum women [37,38]. Longitudinal data also suggested that increasing of depressive symptoms worsens sleep quality [39]. Furthermore, epidemiologic and electroencephalographic sleep studies have shown a role for sleep disturbances in the pathogenesis of depression [40-42], which reminded that prenatal depressive mood may be important area to target in interventions aimed at promoting sleep in pregnant women.

Bivariate analyses indicated a significant relationship between age, gestational age, prenatal depression, perceived stress and sleep quality. 
However, perceived stress did not remain significant in the multiple regression models, suggesting that the relationship between sleep quality and perceived stress may be weak or nonlinear. Alternatively, perceived stress may indirectly influence sleep quality.

\section{Conclusions}

Sleep disorder is a common problem for pregnant women in China, with a prevalence of $87.0 \%$. Furthermore, depressive symptoms, increased age and gestational age are detected to be determinants of sleep quality in pregnant women. Therefore, we recommend that healthcare professionals pay more attention to sleep problems and provide sleep counseling during prenatal checkups, particularly for pregnant women with depressive tendencies and advanced maternal age. Since prenatal depression, increased age and gestational age are determinants of sleep quality in pregnant women, further research should incorporate these variables into a supportive model of sleeprelated prenatal care.

\section{Acknowledgment}

The researchers would like to acknowledge and thank the participants who give their precious time to the study.

\section{Authorship}

Ying Yang completed the work of writing the manuscript as well as data analysis. Jie Li was responsible for study design and final edit of the manuscript. Jing Mao, Zhiying Ye, Huimin Zhao and Yueting Liu conducted the data collection.

\section{Funding information}

This study was supported by the National Natural Science Foundation of China (NNSFC), Grant 71503088.

\section{Competing interest}

The authors declare that there is no conflict of interest.

\section{References}

1. Da CD, Dritsa M, Verreault N, Balaa C, Kudzman J, et al. (2010) Sleep problems and depressed mood negatively impact health-related quality of life during pregnancy. Arch Womens Ment Health 13: 249-257. [Crossref]

2. Sharma S, Franco R (2004) Sleep and its disorders in pregnancy. WMJ 103: 48-52. [Crossref]

3. National Sleep Foundation (2015) Pregnancy and Sleep [updated 2017]. http:/ sleepfoundation.org/sleep-topics/pregnancy-and-sleep.

4. National Sleep Foundation (2010) 2010 sleep and ethnicity [updated 2010]. http:// sleepfoundation.org/sleep-polls-data/sleep-in-america-poll/2010-sleep-and-ethnicity.

5. Zhang Y (2016) Sleep quality and related factors among pregnant women in Xuzhou City. Chin J School Doctor 30: 11-13.

6. Mindell JA, Cook RA, Nikolovski J (2015) Sleep patterns and sleep disturbances across pregnancy. Sleep Med 16: 483-488. [Crossref]

7. Hung HM, Tsai PS, Ko SH, Chen CH (2013) Patterns and predictors of sleep quality in Taiwanese pregnant women. MCN Am J Matern Child Nurs 38: 95-101. [Crossref]

8. Tsai S, Lee P, Lin J, Lee C (2016) Cross-sectional and longitudinal associations between sleep and health-related quality of life in pregnant women: A prospective observational study. Int J Nurs Stud 56: 45-53. [Crossref]

9. Sut HK, Asci O, Topac N (2016) Sleep Quality and Health-Related Quality of Life in Pregnancy. J Perinat Neonatal Nurs 34: 302-309. [Crossref]

10. Facco FL, Kramer J, Ho KH, Zee PC, Grobman WA (2010) Sleep disturbances in pregnancy. Obstet Gynecol 115: 77-83. [Crossref]

11. Polo-Kantola P, Aukia L, Karlsson H, Karlsson L, Paavonen EJ (2017) Sleep quality during pregnancy: associations with depressive and anxiety symptoms. Acta Obstet Gynecol Scand 96: 198-206. [Crossref]

12. Rumble M, White KH, Benca RM (2015) Sleep Disturbances in Mood Disorders. Psychiatr Clin North Am 38: 743-759. [Crossref]

13. Okun ML, Kiewra K, Luther JF, Wisniewski SR, Wisner KL (2011) Sleep disturbances in depressed and nondepressed pregnant women. Depress Anxiety 28: 676-685. [Crossref]

14. Skouteris H, Germano C, Wertheim EH, Paxton SJ, Milgrom J (2008) Sleep quality and depression during pregnancy: a prospective study. J Sleep Res 17: 217-220. [Crossref]

15. Effati- Daryani F, Mirghafourvand M, Mohammad-Alizadeh-Charandabi S, ShiriSarand F, Zarei S (2017) Sleep quality and its relationship with quality of life in Iranian pregnant women. Int J Nurs Pract 23: e12518. [Crossref]

16. Buysse DJ, Reynolds CF 3rd, Monk TH, Berman SR, Kupfer DJ (1989) The Pittsburgh Sleep Quality Index: a new instrument for psychiatric practice and research. Psychiatry Res 28: 193-213. [Crossref]

17. Liu XC, Tang MQ, Hu L, Wang AZ (1996) Reliability and validity of the Pittsburgh sleep quality index. Chin J Psychiatry 29: 103-107.

18. Cox JL, Holden JM, Sagovsky R (1987) Detection of postnatal depression. Developmen of the 10-item Edinburgh Postnatal Depression Scale. Br J Psychiatry 150: 782-786. [Crossref]

19. Cox JL, Holden JM (2003) Perinatal mental health: a guide to the Edinburgh Postnatal Depression Scale. London, Gaskell: Royal College of Psychiatrists.

20. Peng T, Wang L, Jin YZ, Fan XD (1994) The application of EPDS on screening for postpartum depression. Chinese Mental Health Journal 8: 18-19.

21. Wang Y, Guo X, Lau Y, Chan KS, Yin L, Chen J (2009) Psychometric evaluation of the Mainland Chinese version of the Edinburgh Postnatal Depression Scale. Int J Nurs Stud 46: 813-823. [Crossref]

22. Cohen S, Kamarck T, Mermelstein R (1983) A global measure of perceived stress. $J$ Health Soc Behav 24: 385-396. [Crossref]

23. Leung DY, Lam TH, Chan SS (2010) Three versions of Perceived Stress Scale: validation in a sample of Chinese cardiac patients who smoke. BMC Public Health 10: 513 .

24. Zimet GD, Powell SS, Farley GK, Werkman S, Berkoff KA (1990) Psychometric characteristics of the Multidimensional Scale of Perceived Social Support. J Pers Assess 55: 610-617. [Crossref]

25. Dahlem NW, Zimet GD, Walker RR (1991) The Multidimensional Scale of Perceived Social Support: a confirmation study. J Clin Psychol 47: 756-761. [Crossref]

26. Okun ML, Schetter CD, Glynn LM (2011) Poor sleep quality is associated with preterm birth. Sleep 34: 1493-1498. [Crossref]

27. Sharma SK, Nehra A, Sinha S, Soneja M, Sunesh K, et al. (2016) Sleep disorders in pregnancy and their association with pregnancy outcomes: a prospective observational study. Sleep Breath 20: 87-93. [Crossref]

28. Zafarghandi N, Hadavand S, Davati A, Mohseni SM, Kimiaiimoghadam F, et al (2012) The effects of sleep quality and duration in late pregnancy on labor and fetal outcome. $J$ Matern Fetal Neonatal Med 25: 535-537. [Crossref]

29. Xie XH, Wang Y, Huang XX, Shao H (2012) Investigation of the status of sleep quality in hospitalized preterm labour women. J Nurs Admin 12: 397-405.

30. Van Ravesteyn LM, Tulen JH, Kamperman AM, Raats ME, Schneider AJ, et al. (2014) Perceived sleep quality is worse than objective parameters of sleep in pregnant women with a mental disorder. J Clin Sleep Med 10: 1137-1141. [Crossref]

31. Qin C, Mi C, Xia A, Chen W, Chen C, Li Y, et al. (2017) A first look at the effects of long inter-pregnancy interval and advanced maternal age on perinatal outcomes: A retrospective cohort study. Birth. [Crossref]

32. Cao HR (2014) Influence of peer education on sleep quality of elderly parturient women. Modern Clinical Nursing 13: 36-39.

33. Cai XH, Zhang HG, Xu XF, Xuan MY, Yu CY, et al. (2010) [An epidemiological study on the sleep disorders of pregnant women in Wenshou, Zhejiang province]. Zhonghua Liu Xing Bing Xue Za Zhi 31: 597-599. [Crossref]

34. Qiu C, Gelaye B, Zhong Q, Enquobahrie DA, Frederick IO, Williams MA (2016) Construct validity and factor structure of the Pittsburgh Sleep Quality Index among pregnant women in a Pacific-Northwest cohort. Sleep Breath 20: 293-301. [Crossref]

35. Volkovich E, Tikotzky L, Manber R (2016) Objective and subjective sleep during 
pregnancy: links with depressive and anxiety symptoms. Arch Womens Ment Health 19: 173-181. [Crossref]

36. Taylor DJ, Lichstein KL, Durrence HH, Reidel BW, Bush AJ (2005) Epidemiology of insomnia, depression, and anxiety. Sleep 28: 1457-1464. [Crossref]

37. Posmontier B (2008) Sleep quality in women with and without postpartum depression. J Obstet Gynecol Neonatal Nurs 37: 722-737. [Crossref]

38. Goyal D Gay CL, Lee KA (2007) Patterns of sleep disruption and depressive symptoms in new mothers. J Perinat Neonatal Nurs 21: 123-129. [Crossref]

39. Dew MA, Reynolds CF 3rd, Monk TH, Buysse DJ, Hoch CC, et al. (1994) Psychosocial correlates and sequelae of electroencephalographic sleep in healthy elders. $J$ Gerontol 49: P8-P18. [Crossref]

40. Ford DE, Kamerow DB (1989) Epidemiologic study of sleep disturbances and psychiatric disorders. An opportunity for prevention? JAMA 262: 1479-1484. [Crossref]

41. Hayase M, Shimada M, Seki H (2014) Sleep quality and stress in women with pregnancy-induced hypertension and gestational diabetes mellitus. Women Birth 27 190-195. [Crossref]

42. Kupfer DJ, Frank E, Grochocinski VJ, Gregor M, McEachran AB (1988) Electroencephalographic sleep profiles in recurrent depression. A longitudinal investigation. Arch Gen Psychiatry 45: 678-681.

Copyright: $@ 2017$ Yang Y. This is an open-access article distributed under the terms of the Creative Commons Attribution License, which permits unrestricted use, distribution, and reproduction in any medium, provided the original author and source are credited. 